\title{
Níveis nutricionais de fósforo disponível para aves de corte ISA Label criadas em semiconfinamento ${ }^{1}$
}

\author{
Sandra Regina Freitas Pinheiro², Nilva Kazue Sakomura33, Dáphinne Cardoso Nagib \\ Nascimento ${ }^{2}$, Leilane Rocha Barros Dourado², João Batista Kochenborger Fernandes ${ }^{4}$, \\ Maria Cristina Thomaz ${ }^{3}$
}

\footnotetext{
1 Projeto financiado pelo CNPq.

2 Pós-graduação em Zootecnia - FCAV - UNESP/Jaboticabal.

${ }^{3}$ Departamento de Zootecnia - FCAV - UNESP/Jaboticabal.

${ }^{4}$ Caunesp - Jaboticabal, SP.
}

RESUMO - Foram realizados três ensaios para determinar os níveis nutricionais de fósforo disponível (Pd) para machos e fêmeas da linhagem ISA Label nas fases inicial (1 a 28 dias), crescimento (28 a 56 dias) e final (56 a 84 dias) criadas em semiconfinamento. Em cada ensaio, 480 aves com idade correspondente à fase de criação foram alojadas em 24 unidades experimentais contendo áreas de abrigo e de pastejo. O delineamento experimental utilizado foi o inteiramente casualizado, em esquema fatorial $4 \times 2$ (níveis de Pd e sexos) com três repetições de 20 aves. Os níveis de fósforo disponível avaliados foram: 0,$25 ; 0,36 ; 0,47$ e $0,58 \%$ na fase inicial; 0,$18 ; 0,31 ; 0,44$ e $0,57 \%$ na fase de crescimento; e 0,$14 ; 0,27 ; 0,40$ e $0,53 \%$ na fase final. Foram avaliados o ganho de peso, consumo de ração, consumo de Pd, conversão alimentar, teores de fósforo, cálcio e cinzas na tíbia e resistência à quebra óssea. De acordo com os resultados, o nível ótimo de Pd na ração na fase inicial, para machos e fêmeas são de 0,39 e $0,49 \%$, que correspondem ao consumo de 3,94 e 3,96 g de Pd/ave, respectivamente. Para a fase de crescimento, recomenda-se $0,35 \%$ de Pd na ração para aves de ambos os sexos, que correspondem a consumo de 8,45 e 6,70 g de Pd/ave. Na fase final, recomendam-se os níveis de 0,32 e 0,30\% de Pd, que correspondem a consumos de 12 e 9,5 g de Pd/ave para machos e fêmeas, respectivamente.

Palavras-chave: aves de crescimento lento, cálcio, ossos

\section{Nutritional levels of available phosphorus for ISA Label broilers chickens reared in free-range system}

\begin{abstract}
It was performed three trials to determine the nutritional levels of available phosphorus (aP) for males and females of the strain ISA Label in the starter ( 1 to 28 days), growing (28 to 56 days) and finisher (56 to 84 days) phases, reared in a free-range system. In each trial, 480 birds with age corresponding to rearing phase were housed in 24 experimental units with shelter and pasture areas. It was used a complete random experimental design, in a $4 \times 2$ factorial scheme (levels of aP and sexes) with three replicates of 20 birds. The levels of aP evaluated were the following: $0.25,0.36,0.47$ and $0.58 \%$ in the starter phase; $0.18,0.31,0.44$ and $0.57 \%$ in the growing phase; and $0.14,0.27,0.40$ and $0.53 \%$ in the finisher phase. Body weight gain, feed intake, aP intake, feed conversion, contents of phosphorus, calcium and ash in the tibia and bone breaking strength were evaluated. According to results, the optimum dietary aP levels in the starter phase, for males and females, are 0.39 and $0.49 \%$, which correspond to the intake of 3.94 and $3.96 \mathrm{~g}$ of aP/bird, respectively. For the growing phase, it is recommended $0.35 \%$ of aP in the diet for birds of both sexes, which correspond to an intake of 8.45 and $6.70 \mathrm{~g}$ of aP/bird. In the finisher phase, it is recommended the levels 0.32 and $0.30 \%$ of aP, which corresponds to intakes of $12 \mathrm{~g}$ and $9.5 \mathrm{~g}$ aP/bird for males and females, respectively.
\end{abstract}

Key Words: bones, calcium, slow-growing birds

\section{Introdução}

Na criação comercial de aves alternativas, utiliza-se material genético melhorado, em geral, híbridos que possuem boa produtividade e rusticidade, porém com menor taxa de crescimento em relação aos frangos convencionais. Apesar da crescente demanda por produtos oriundos dessas aves, verifica-se uma carência em pesquisas avaliando suas exigências nutricionais. Geralmente os programas nutricionais destas linhagens são baseados nas 
recomendações de tabelas e trabalhos realizados com frangos de corte. Do custo total de produção cerca de $70 \%$ é atribuído à alimentação, sendo as fontes de proteína, fósforo e energia, os mais onerosos (Brugalli et al., 1999; Runho et al., 2001). Nas rações de monogástricos geralmente é necessária a suplementação de fósforo, pois o milho e o farelo de soja, ingredientes básicos das rações, possuem baixos teores de fósforo e o conteúdo presente nesses grãos está em grande parte na forma de fósforo fítico, ou seja, pouco disponível. O fósforo é o segundo mineral mais abundante na composição dos tecidos animais, sendo $80 \%$ presentes nos ossos e dentes, e o restante está distribuído entre fluidos e outros tecidos (Underwood \& Suttle, 1999).

Poucos estudos sobre as exigências de fósforo para aves de crescimento lento têm sido realizados, havendo diversos estudos com frangos de corte. Gomes et al. (1994) estimaram os valores de 0,34 e 0,33\% de Pd na ração, nas fases de crescimento e terminação, respectivamente. Em outro trabalho, Gomes et al. (2004) determinaram níveis de Pd de 0,442 e $0,454 \%$ para fase de crescimento e 0,31 e $0,24 \%$ para fase de terminação, para machos e fêmeas, respectivamente.

Objetivando avaliar a exigência de Pd e o efeito da granulometria na biodisponibilidade do fósforo da farinha de carne e ossos para pintos de 1 a 21 dias, Brugalli et al. (1999) recomendaram 0,426\% de Pd (0,142\% Pd/Mcal EM) na ração. Avaliando a exigência de Pd para frangos de corte machos e fêmeas de 1 a 21 dias, Runho et al. (2001) sugeriram 0,45 ou $0,148 \%$ de Pd/Mcal de EM na ração.

Essas informações refletem as divergências que podem ocorrer até mesmo para frangos de corte. Dessa forma, são necessários estudos para determinar a exigência de fósforo para aves de linhagens alternativas, cujas características do crescimento diferem daquelas observadas para frangos de corte.

Objetivou-se estimar as exigências de fósforo disponível para aves da linhagem ISA Label de ambos os sexos criadas em semiconfinamento nas fases inicial ( 1 a 28 dias), de crescimento (28 a 56 dias) e final (56 a 84 dias).

\section{Material e Métodos}

Foram realizados três ensaios no Setor de Avicultura do Departamento de Zootecnia da Faculdade de Ciências Agrárias e Veterinárias - FCAV/UNESP, Câmpus de Jaboticabal, São Paulo, no período de 16 de outubro de 2006 a 8 de janeiro de 2007, para determinação das exigências de fósforo disponível (Pd) para aves da linhagem ISA Label, de ambos os sexos, criadas em sistema de semiconfinamento nas fases inicial (1 a 28 dias), crescimento (28 a 56 dias) e final (56 a 84 dias). Em cada ensaio, foram utilizadas 480 aves
(240 machos e 240 fêmeas), distribuídas no delineamento experimental inteiramente casualizado, em esquema fatorial 4 × 2 (níveis de fósforo disponível e sexo) e três repetições de 20 aves. Foi criado um lote reserva de aves, que foram utilizadas nas fases de crescimento e final, sendo as mesmas alojadas em galpão convencional até o $28^{\circ}$ e $56^{\circ}$ dia de idade, sendo transferidas para as instalações experimentais no início de cada fase. As aves receberam rações que atendiam as suas exigências nutricionais em todos os nutrientes, de acordo com Rostagno et al. (2005). As instalações experimentais consistiram de 24 piquetes, cada um dispondo de um abrigo $\left(3,13 \mathrm{~m}^{2}\right)$ e área de pastejo de $\left(72,87 \mathrm{~m}^{2}\right)$. Os abrigos possuíam as laterais teladas, providas de cortinas e cobertura de telha de cimento amianto, sendo o piso forrado com cama de maravalha. Cada abrigo foi equipado com um comedouro tubular e um bebedouro tipo pendular. A área de pastejo, cercada por tela galvanizada, possuía predominantemente gramíneas do gênero Paspalum. Na fase inicial, as aves alojadas com um dia de idade, permaneceram limitadas ao abrigo até o $28^{\circ}$ dia. Nas fases subsequentes, as aves tiveram acesso à área de pastejo, eram soltas diariamente às $8 \mathrm{~h}$, e recolhidas para $\mathrm{o}$ abrigo às $18 \mathrm{~h}$.

Para cada fase, foram formuladas rações basais (Tabela 1), compostas principalmente por milho e farelo de soja, considerando as exigências nutricionais de energia metabolizável, proteína bruta e aminoácidos (lisina e metionina + cistina) conforme pesquisas realizadas na FCAV/Unesp, Jaboticabal. Os outros aminoácidos seguiram as relações aminoacídicas preconizadas por Rostagno et al. (2005). As rações basais foram suplementadas com fosfato bicálcico em substituição ao calcário e inerte, resultando em rações isonutritivas contendo 0,$25 ; 0,36 ; 0,47$ e $0,58 \%$ de Pd na fase inicial, 0,$18 ; 0,31 ; 0,44$ e $0,57 \%$ de Pd na fase de crescimento e 0,$14 ; 0,27 ; 0,40$ e $0,53 \%$ de Pd na fase final.

As aves receberam ração e água à vontade, sendo criadas somente com luz natural.

Para avaliação do desempenho, foram registrados dados de ganho de peso (g/ave), consumo de ração (g/ave), consumo de fósforo disponível (g/ave) e conversão alimentar (g ração consumida/g de ganho de peso) e, para estudo dos parâmetros ósseos, os teores de cálcio (\%), fósforo (\%) e cinzas (\%) na tíbia e resistência à quebra óssea (kgf/mm). Para avaliação dos parâmetros dos ossos, no final de cada ensaio, três aves de cada parcela (72 no total), com peso corporal próximo ao da média da parcela $( \pm 10 \%)$, foram submetidas a jejum alimentar de 12 horas e abatidas por deslocamento cervical para retirada das tíbias. As tíbias foram descarnadas e fervidas em água destilada por 5 minutos para facilitar a retirada dos resíduos de carne. A fíbula e as cartilagens também foram removidas. 
Tabela 1 - Composição das rações basais fornecidas nas fases inicial (1 a 28 dias), de crescimento (28 a 56 dias) e final (56 a 84 dias)

\begin{tabular}{|c|c|c|c|}
\hline \multirow[b]{3}{*}{ Composição em ingredientes } & ições per & centuais & \\
\hline & \multicolumn{3}{|c|}{ Fase } \\
\hline & Inicial & Crecimento & Final \\
\hline Milho & 61,364 & 63,634 & 70,200 \\
\hline Farelo de soja $45 \%$ & 33,750 & 30,706 & 24,258 \\
\hline Óleo de soja & 0,621 & 1,627 & 1,983 \\
\hline Sal comum & 0,431 & 0,330 & 0,255 \\
\hline Suplemento mineral ${ }^{1}$ & 0,100 & 0,100 & 0,100 \\
\hline Suplemento vitamínico ${ }^{2}$ & 0,100 & 0,100 & 0,100 \\
\hline DL-metionina 99\% & 0,136 & 0,169 & 0,098 \\
\hline L-lisina $\mathrm{HCl} \mathrm{78 \%}$ & 0,066 & 0,115 & 0,000 \\
\hline Cloreto de colina $70 \%$ & 0,070 & 50 & 0,050 \\
\hline Fosfato bicálcico & 0,758 & 0,399 & 0,217 \\
\hline Calcário calcítico & 1,706 & 1,769 & 1,738 \\
\hline Inerte $^{3}$ & 0,900 & 1,001 & 1,001 \\
\hline \multicolumn{4}{|l|}{ Composição nutricional calculada } \\
\hline Proteína bruta (\%) & 20,500 & 19,371 & 16,850 \\
\hline Energia metabolizável (kcal/kg) & 2.900 & 3.000 & 3.100 \\
\hline Cálcio (\%) & 0,940 & 0,870 & 0,800 \\
\hline Fósforo total (\%) & 0,466 & 0,389 & 0,337 \\
\hline Fósforo disponível (\%) & 0,250 & 0,180 & 0,140 \\
\hline Sódio (\%) & 0,190 & 0,150 & 0,120 \\
\hline Metionina + cistina digestível (\%) & 0,710 & 0,716 & 0,597 \\
\hline Lisina digestível (\%) & 1,041 & 1,006 & 0,766 \\
\hline Treonina digestível (\%) & 0,696 & 0,654 & 0,570 \\
\hline Arginina digestível (\%) & 1,301 & 1,212 & 1,029 \\
\hline Triptofano digestível (\%) & 0,226 & 0,210 & 0,178 \\
\hline Valina digestível (\%) & 0,866 & 0,815 & 0,714 \\
\hline \multicolumn{4}{|c|}{$\begin{array}{l}{ }^{1} \text { Por kg de ração: manganês - } 75 \text { mg; ferro - } 50 \text { mg; zinco - } 70 \text { mg; cobre - } 8.50 \text { mg; } \\
\text { cobalto - } 2 \text { mg; iodo - } 1.5 \text { mg; e veículo q.s.p. - } 1.000 \text { g. } \\
2 \text { Por kg de ração: vit. A - } 12.000 \text { UI; vit. } \mathrm{D}_{3}-2.200 \mathrm{UI} \text {; vit. E - } 30 \text { UI; vit. } \mathrm{B}_{1} \text { - } \\
2,2 \mathrm{mg} \text {; vit. } \mathrm{B}_{2}-6 \mathrm{mg} \text {; vit. } \mathrm{B}_{6}-3,3 \mathrm{mg} \text {; vit. } \mathrm{B}_{12}-16 \mathrm{mg} \text {; niacina - } 2.500 \mathrm{mg} \text {; ácido } \\
\text { pantotênico - } 13 \mathrm{mg} \text {; vit. } \mathrm{K}_{-3}-2,5 \mathrm{mg} \text {; ácido fólico - } 1 \mathrm{mg} \text {; selênio - } 0,12 \mathrm{mg} \text {; } \\
\text { antioxidante - } 10 \mathrm{mg} \text {; e veículo q.s.p. - } 1.000 \mathrm{~g} \text {. } \\
{ }^{3} \text { Areia lavada. }\end{array}$} \\
\hline
\end{tabular}

As medidas de resistência à quebra óssea foram realizadas nas tíbias direitas, in natura, previamente descarnadas, utilizando-se uma máquina universal de ensaios mecânicos, marca EMIC ${ }^{\circledR}$ - modelo DL100 KW, sendo os valores expressos em quilograma força por milímetro (kgf/mm). A carga aplicada foi de 2000 Newtons na região central e a velocidade de descida da carga foi de $5 \mathrm{~mm} / \mathrm{s}$, sendo registrada a força aplicada no momento anterior à ruptura do osso.

Para as análises de cálcio, fósforo e cinzas foram utilizadas as tíbias esquerdas, que foram identificadas com placas de alumínio, mergulhadas em éter de petróleo por 48 horas, e posteriormente secas em estufa de ventilação forçada a $60^{\circ} \mathrm{C}$ por 48 horas. Em seguida as tíbias foram trituradas em moinho de bola. As análises dos minerais foram realizadas de acordo com a metodologia da via úmida e as cinzas determinadas em mufla a $600^{\circ} \mathrm{C}$, conforme descrito por Silva \& Queiroz (2002), sendo expressos na matéria seca desengordurada.
Os dados foram submetidos às análises de variância e os níveis de Pd foram desdobrados em regressão polinomial. As estimativas dos níveis ótimos de fósforo disponível foram feitas por meio dos modelos linear response plateau (LRP) e/ou quadrático e quando possível o ajuste de ambos os modelos, estimou-se o nível ótimo pela primeira interseção da equação quadrática com o platô do LRP, conforme descrito por Sakomura \& Rostagno (2007). Para aquelas variáveis cujos efeitos dos níveis de Pd foram detectados pela análise de variância, mas não foi possível ajustar nenhum dos modelos de regressão propostos, utilizou-se o teste Duncan a 5\% de probabilidade para comparar as médias. As análises estatísticas foram realizadas utilizando-se o programa computacional SAS ${ }^{\circledR} 9.0$ (2009).

\section{Resultados e Discussão}

Para a fase inicial, os níveis de fósforo disponível da ração influenciaram $(\mathrm{P}<0,05)$ todas as variáveis estudadas, exceto a resistência à quebra óssea (Tabela 2). Da mesma forma, o sexo das aves teve efeito $(\mathrm{P}<0,01)$ no desempenho, embora não tenha influenciado os parâmetros ósseos. Não houve interação $(\mathrm{P}>0,05)$ entre os níveis de fósforo disponível e o sexo para nenhuma das variáveis avaliadas, com exceção do ganho de peso, e isso indica que machos e fêmeas respondem de maneira diferenciada aos níveis crescentes de fósforo disponível das rações.

O consumo de ração aumentou de forma linear crescente ( $\mathrm{P}<0,05)$ de acordo com os níveis de fósforo disponível das rações (Tabela 3). De acordo com McDowell (1992), o primeiro sinal clínico de deficiência de fósforo é a perda do apetite, pois há deficiência energética para o metabolismo e isso leva a perda de peso e redução na produção, devido à participação do fósforo na molécula da adenosina trifosfato (ATP), que armazena energia em suas ligações de fosfato. Rações deficientes em fósforo prejudicam a formação da molécula de ATP e, consequentemente, causam distúrbios no metabolismo energético.

O consumo de fósforo disponível pelas aves de ambos os sexos aumentou linearmente $(\mathrm{P}<0,01)$ com os crescentes níveis de fósforo disponível das rações. Esse efeito foi devido ao aumento linear no consumo de ração e na concentração de fósforo disponível.

As respostas de ganho de peso dos machos foram ajustadas pelos modelos polinomial quadrático e LRP, estimando-se os níveis de Pd de 0,478 e 0,349\%, respectivamente. Considerando a combinação de ambos os modelos, por meio da primeira interseção da equação quadrática com o platô do LRP, a estimativa do nível ótimo foi de $0,394 \%$ de Pd, sendo intermediário àqueles obtidos 
Tabela 2 - Desempenho de aves ISA Label, machos e fêmeas, alimentadas com rações contendo quatro níveis de Pd no período de um a 28 dias de idade

\begin{tabular}{|c|c|c|c|c|c|c|c|c|c|c|}
\hline \multirow[t]{2}{*}{ Variável } & \multicolumn{3}{|c|}{ Probabilidade } & \multirow[t]{2}{*}{ Sexo } & \multicolumn{4}{|c|}{ Nível de fósforo disponível (\%) } & \multirow[t]{2}{*}{ Média } & \multirow[t]{2}{*}{ CV (\%) } \\
\hline & $\mathrm{Pd}$ & Sexo & $\mathrm{Pd}^{*} \operatorname{sexo}$ & & 0,25 & 0,36 & 0,47 & 0,58 & & \\
\hline \multirow[t]{3}{*}{ Consumo de ração (g/ave) } & 0,0178 & 0,0004 & 0,1925 & Macho & 980 & 1057 & 1045 & 1037 & 1030 & 3,59 \\
\hline & & & & Fêmea & 928 & 933 & 1001 & 995 & 964 & \\
\hline & & & & Média & 954 & 995 & 1023 & 1016 & & \\
\hline \multirow[t]{3}{*}{ Consumo de Pd (g/ave) } & 0,0001 & 0,0004 & 0,2834 & Macho & 2,45 & 3,80 & 4,91 & 6,02 & 4,29 & 3,36 \\
\hline & & & & Fêmea & 2,32 & 3,36 & 4,70 & 5,77 & 4,04 & \\
\hline & & & & Média & 2,38 & 3,58 & 4,81 & 5,89 & & \\
\hline \multirow[t]{3}{*}{ Ganho de peso (g/ave) } & 0,0001 & 0,0001 & 0,0410 & Macho & 453 & 538 & 526 & 532 & 512 & 3,42 \\
\hline & & & & Fêmea & 428 & 452 & 468 & 467 & 454 & \\
\hline & & & & Média & 441 & 495 & 497 & 500 & & \\
\hline \multirow[t]{3}{*}{ Conversão alimentar (g/g) } & 0,0192 & 0,0103 & 0,4215 & Macho & 2,161 & 1,965 & 1,984 & 1,952 & 2,016 & 4,50 \\
\hline & & & & Fêmea & 2,169 & 2,065 & 2,142 & 2,129 & 2,126 & \\
\hline & & & & Média & 2,165 & 2,015 & 2,063 & 2,040 & & \\
\hline \multirow[t]{3}{*}{ Fósforo na tíbia (\%) } & 0,0480 & 0,7066 & 0,3866 & Macho & 9,00 & 9,74 & 10,02 & 9,82 & 9,65 & 3,99 \\
\hline & & & & Fêmea & 9,52 & 9,72 & 9,78 & 9,80 & 9,71 & \\
\hline & & & & Média & 9,26 & 9,73 & 9,90 & 9,81 & & \\
\hline \multirow[t]{3}{*}{ Cálcio na tíbia (\%) } & 0,0146 & 0,6295 & 0,5413 & Macho & 16,75 & 18,10 & 18,38 & 18,29 & 17,88 & 5,46 \\
\hline & & & & Fêmea & 17,12 & 18,24 & 17,21 & 18,17 & 17,69 & \\
\hline & & & & Média & 16,93 & 18,17 & 17,80 & 18,23 & & \\
\hline \multirow[t]{3}{*}{ Cinzas na tíbia (\%) } & 0,0092 & 0,1498 & 0,3286 & Macho & 45,76 & 49,84 & 49,42 & 49,49 & 48,62 & 3,11 \\
\hline & & & & Fêmea & 46,53 & 48,82 & 48,52 & 46,92 & 47,70 & \\
\hline & & & & Média & 46,14 & 49,33 & 48,97 & 48,21 & & \\
\hline \multirow{3}{*}{$\begin{array}{l}\text { Resistência à quebra } \\
\text { óssea (kgf/mm) }\end{array}$} & 0,8776 & 0,0564 & 0,6838 & Macho & 13,40 & 15,03 & 14,39 & 13,27 & 14,02 & 14,14 \\
\hline & & & & Fêmea & 12,64 & 11,92 & 12,88 & 12,41 & 12,45 & \\
\hline & & & & Média & 13,02 & 13,48 & 13,60 & 12,84 & & \\
\hline
\end{tabular}

CV = coeficiente de variação.

com o modelo LRP e o quadrático, correspondendo ao consumo de 3,94 g de Pd/ave. Para as fêmeas, observou-se comportamento similar ao dos machos. A estimativa do nível de Pd obtida pelo modelo quadrático foi de $0,535 \%$ e pelo LRP foi de $0,434 \%$. Aplicando a combinação desses modelos, foi estimado o nível intermediário de 0,489\% de Pd na ração, correspondendo ao consumo de 4,96 g de Pd/ave, para maximizar o GP das fêmeas, durante o período de 1 a 28 dias.

As diferenças nas exigências de fósforo disponível entre os sexos podem ser decorrentes da maior eficiência alimentar dos machos em relação às fêmeas, pois apresentaram ganho de peso significativamente mais alto sob deficiência de Pd. Esses resultados estão de acordo com os obtidos por Bar et al. (2003) que observaram menor exigência de Pd para o crescimento e deposição de cinzas na tíbia de frangos de corte machos em relação às fêmeas.

A conversão alimentar melhorou $(\mathrm{P}<0,05)$ à medida que o nível de fósforo disponível aumentou de 0,25 para 0,36\%, obtendo adequado ajuste pelo modelo LRP que estimou o nível ótimo de $0,333 \%$ de Pd, para aves de ambos os sexos, resultado inferior aos relatados por Runho et al. (2001), em pesquisa com frangos de corte ( $0,45 \%$ de $\mathrm{Pd})$. Esses autores observaram que o maior nível estudado piorou os resultados e justificaram que o excesso de fósforo reduz a utilização dos nutrientes pelas aves pela formação de complexos insolúveis.
Considerando o teor de fósforo na tíbia, verificou-se ajuste pelos modelos quadrático e LRP e estimativas de 0,486 e $0,389 \%$ de $\mathrm{Pd}$, respectivamente, para melhorar a deposição de fósforo na tíbia. A associação dos modelos quadrático e LRP, estimou o nível de 0,419\% de Pd, equivalendo ao consumo de 4,21 g de Pd/ave, para machos e fêmeas. Resultado similar foi encontrado por Brugalli et al. (1999) que estimaram o nível de 0,392\% de Pd, para pintos de corte de 1 a 21 dias de idade.

O nível de Pd para aves machos e fêmeas, estimado com base nos resultados do teor de cálcio na tíbia, tiveram melhor ajuste pelo modelo LRP, que estimou o nível de 0,346\% de Pd. De acordo com Gonzales \& Sartori (2002), o crescimento dos tecidos no animal tem comportamento característico: esqueleto, músculos e tecido adiposo desenvolvem-se sucessivamente, por meio de maior ou menor taxa específica de crescimento em determinado momento, dependendo da prioridade, dependendo da categoria animal. Considerando que, na fase inicial de vida das aves, o tecido ósseo cresce mais rapidamente que os outros tecidos, espera-se que a deposição de cálcio e fósforo na tíbia seja mais pronunciada nessa fase que nas fases subsequentes.

A deposição de cinzas na tíbia das aves de ambos os sexos foi influenciada $(\mathrm{P}<0,01)$ pelos níveis de fósforo disponível, que, ajustado pelo modelo LRP, foi estimado em 
Tabela 3 - Equações ajustadas, coeficientes de determinação $\left(\mathrm{R}^{2}\right)$ e níveis de Pd estimados (NPd) para aves ISA Label de 1 a 28 dias de idade

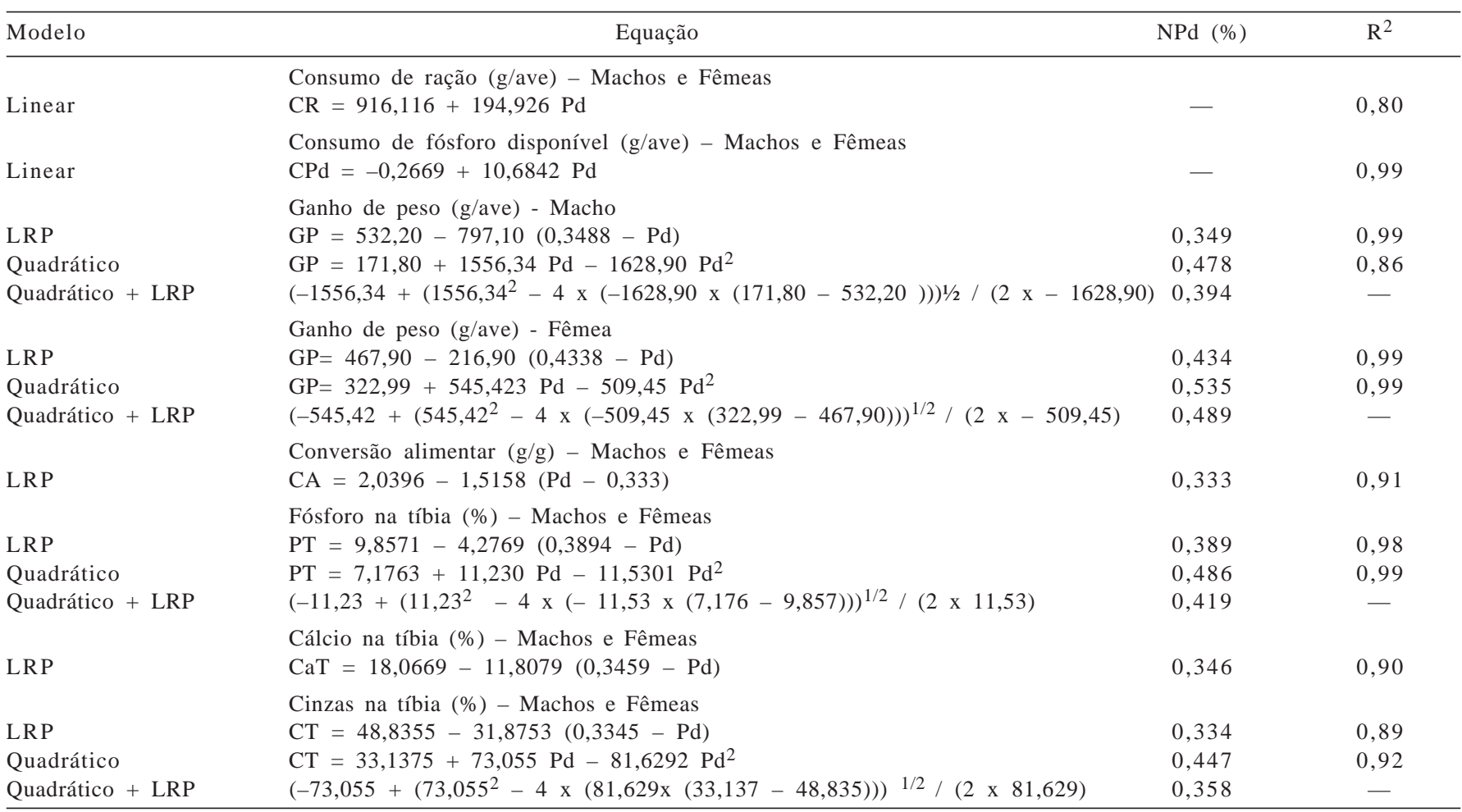

0,334\% e, pela equação quadrática, em $0,447 \%$ como nível ótimo. Pela interseção da curva quadrática com o platô do LRP, estimou-se o nível de $0,358 \%$ de Pd, que corresponde ao consumo de 3,56 g de Pd/ave. Esses valores foram inferiores àqueles observados por Runho et al. (2001), de 0,515 e $0,377 \%$ de Pd, pelos modelos quadrático e LRP, respectivamente, em pesquisa com frangos de corte de $1 \mathrm{a}$ 21 dias. As diferenças entre os resultados desses trabalhos podem ser devidas às rações, ao sistema de criação, às linhagens genéticas, entre outros fatores.

Embora os níveis de fósforo diponível das rações tenham influenciado a deposição de cálcio e fósforo na tíbia das aves, não foi possível detectar efeitos sobre a resistência à quebra óssea. Esse resultado pode ser justificado pelo fato de as aves, na fase inicial de vida, priorizarem o crescimento do tecido ósseo e, consequentemente, aumentar a eficiência para depositar minerais na tíbia, mesmo em rações deficientes em fósforo disponível, o que não compromete a resistência óssea. Outra justificativa seria aquela relatada por Zoollitsch et al. (1996) de que a mobilização óssea de cálcio e fósforo para atender às necessidades metabólicas é um processo natural e que a perda óssea somente compromete a resistência quando há deficiência prolongada.

Vários autores (Brugalli et al., 1999; Runho et al., 2001; Gomes et al., 2004) citaram que os níveis nutricionais necessário para melhorar o desempenho são inferiores àqueles das variáveis ósseas. No entanto, os resultados obtidos neste trabalho para a fase de 1 a 28 dias de idade foram próximos, tanto para variáveis de desempenho quanto para os parâmetros ósseos. Os dados obtidos corroboram os encontrados por Bar et al. (2003), que verificaram que as exigências em fósforo para ganho de peso e deposição de cinzas na tíbia dos frangos de corte em crescimento são similares. As exigências para máximo desempenho e melhores parâmetros ósseos não seguem, portanto, mesmo padrão e isso pode estar associado à idade e ao potencial genético dos animais.

Os níveis de fósforo disponível das rações estudados na fase de crescimento influenciaram $(\mathrm{P}<0,05)$ todas as variáveis, exceto a deposição de cálcio na tíbia (Tabela 4). $\mathrm{O}$ sexo das aves teve efeito $(\mathrm{P}<0,01)$ no consumo de ração e de fósforo disponível, no ganho de peso e na resistência à quebra óssea. Não houve efeito $(\mathrm{P}>0,05)$ da interação entre os níveis de fósforo disponível e o sexo das aves nas variáveis analisadas, exceto o consumo de fósforo disponível. Pela análise de variância, detectou-se efeito $(\mathrm{P}<0,05)$ dos níveis de fósforo disponível no consumo de ração, contudo, não foi possível ajuste dos resultados pelos modelos propostos. Pelo teste de médias, o menor consumo de ração foi obtido com o nível mais baixo $(0,18 \%)$ e, conforme aumentaram os níveis de fósforo disponível, o 
Tabela 4 - Desempenho de aves ISA Label alimentadas com rações contendo quatro níveis de fósforo disponível no período de 28 a 56 dias de idade

\begin{tabular}{|c|c|c|c|c|c|c|c|c|c|c|}
\hline \multirow[t]{2}{*}{ Variável } & \multicolumn{3}{|c|}{ Probabilidade } & \multirow[t]{2}{*}{ Sexo } & \multicolumn{4}{|c|}{ Nível de fósforo disponível (\%) } & \multirow[t]{2}{*}{ Média } & \multirow[t]{2}{*}{$\mathrm{CV}(\%)$} \\
\hline & Fósforo disponível & Sexo & $\mathrm{Pd}^{*}$ sexo & & 0,18 & 0,31 & 0,44 & 0,57 & & \\
\hline Consumo de ração (g/ave) & 0,0006 & 0,0001 & 0,4961 & $\begin{array}{l}\text { Macho } \\
\text { Fêmea } \\
\text { Média }\end{array}$ & $\begin{array}{c}2253 \\
1818 \\
2035 C\end{array}$ & $\begin{array}{c}2404 \\
1879 \\
2142 B\end{array}$ & $\begin{array}{c}2397 \\
1922 \\
2160 \mathrm{AB}\end{array}$ & $\begin{array}{c}2495 \\
1961 \\
2228 A\end{array}$ & $\begin{array}{l}2387 \\
1895\end{array}$ & 2,90 \\
\hline Consumo de fósforo disponível (g/ave) & 0,0001 & 0,0001 & 0,0001 & $\begin{array}{l}\text { Macho } \\
\text { Fêmea } \\
\text { Média }\end{array}$ & $\begin{array}{l}4,05 \\
3,27 \\
3,66\end{array}$ & $\begin{array}{l}7,45 \\
5,83 \\
6,64\end{array}$ & $\begin{array}{c}10,54 \\
8,46 \\
9,50\end{array}$ & $\begin{array}{l}14,22 \\
11,17 \\
12,70\end{array}$ & $\begin{array}{l}9,07 \\
7,18\end{array}$ & 3,35 \\
\hline Ganho de peso (g/ave) & 0,0044 & 0,001 & 0,8202 & $\begin{array}{l}\text { Macho } \\
\text { Fêmea } \\
\text { Média }\end{array}$ & $\begin{array}{c}1031 \\
808 \\
920 \mathrm{~B}\end{array}$ & $\begin{array}{c}1125 \\
874 \\
1.000 \mathrm{~A}\end{array}$ & $\begin{array}{c}1093 \\
876 \\
984 \mathrm{~A}\end{array}$ & $\begin{array}{c}1118 \\
874 \\
996 \mathrm{~A}\end{array}$ & $\begin{array}{c}1092 \\
858\end{array}$ & 3,70 \\
\hline Conversão alimentar (g/g) & 0,0256 & 0,2752 & 0,7214 & $\begin{array}{l}\text { Macho } \\
\text { Fêmea } \\
\text { Média }\end{array}$ & $\begin{array}{l}2,187 \\
2,250 \\
2,218\end{array}$ & $\begin{array}{l}2,136 \\
2,151 \\
2,144\end{array}$ & $\begin{array}{l}2,193 \\
2,195 \\
2,194\end{array}$ & $\begin{array}{l}2,232 \\
2,243 \\
2,237\end{array}$ & $\begin{array}{l}2,187 \\
2,210\end{array}$ & 2,25 \\
\hline Fósforo na tíbia(\%) & 0,019 & 0,4081 & 0,7877 & $\begin{array}{l}\text { Macho } \\
\text { Fêmea } \\
\text { Média }\end{array}$ & $\begin{array}{l}8,48 \\
8,41 \\
8,44\end{array}$ & $\begin{array}{l}8,84 \\
8,94 \\
8,89\end{array}$ & $\begin{array}{l}9,13 \\
8,82 \\
8,98\end{array}$ & $\begin{array}{l}9,17 \\
8,89 \\
9,03\end{array}$ & $\begin{array}{l}8,90 \\
8,77\end{array}$ & 4,48 \\
\hline Cálcio na tíbia (\%) & 0,6268 & 0,7120 & 0,4958 & $\begin{array}{l}\text { Macho } \\
\text { Fêmea } \\
\text { Média }\end{array}$ & $\begin{array}{l}16,94 \\
17,10 \\
17,02\end{array}$ & $\begin{array}{l}17,15 \\
17,85 \\
17,50\end{array}$ & $\begin{array}{l}18,04 \\
17,35 \\
17,69\end{array}$ & $\begin{array}{l}17,96 \\
17,20 \\
17,58\end{array}$ & $\begin{array}{l}17,52 \\
17,38\end{array}$ & 5,40 \\
\hline Cinzas na tíbia (\%) & 0,0068 & 0,7347 & 0,3785 & $\begin{array}{l}\text { Macho } \\
\text { Fêmea } \\
\text { Média }\end{array}$ & $\begin{array}{l}45,46 \\
45,72 \\
45,59\end{array}$ & $\begin{array}{l}47,46 \\
49,17 \\
48,32\end{array}$ & $\begin{array}{l}48,26 \\
47,09 \\
47,68\end{array}$ & $\begin{array}{l}49,07 \\
47,24 \\
48,16\end{array}$ & $\begin{array}{l}47,56 \\
47,30\end{array}$ & 3,89 \\
\hline Resistência à quebra óssea (kgf/mm) & 0,0013 & 0,0001 & 0,5879 & $\begin{array}{l}\text { Macho } \\
\text { Fêmea } \\
\text { Média }\end{array}$ & $\begin{array}{l}16,72 \\
11,28 \\
14,00\end{array}$ & $\begin{array}{l}20,56 \\
17,33 \\
18,94\end{array}$ & $\begin{array}{l}19,45 \\
16,63 \\
18,04\end{array}$ & $\begin{array}{l}19,51 \\
15,03 \\
17,27\end{array}$ & $\begin{array}{l}19,06 \text { a } \\
15,07 \text { b }\end{array}$ & 10,55 \\
\hline
\end{tabular}

Médias seguidas de letras iguais nas linhas (maiúscula) não diferem $(\mathrm{P}>0,05)$ entre si pelo teste Duncan. CV = coeficiente de variação.

consumo de ração também aumentou. Esse resultado também foi constatado na fase anterior e pode ser justificado pela deficiência de fósforo, que prejudica a formação de ATP acarretando distúrbios no metabolismo energético. Gomes et al. (1994) avaliaram a exigência de fósforo disponível para frangos de corte na fase de crescimento e observaram menor consumo de ração no nível mais baixo (0,17\%), enquanto os demais níveis não promoveram diferenças no consumo. A interação entre o consumo de fósforo disponível e sexo resultou em equações distintas para machos e fêmeas, e esse efeito está relacionado às variações no consumo de ração entre os sexos (Tabela 5).

O ganho de peso foi afetado $(\mathrm{P}<0,05)$ pelos níveis de fósforo disponível nas rações, porém nenhum dos modelos estudados ajustou-se adequadamente ao comportamento dos resultados, por isso, aplicou-se o teste Duncan para comparar as médias. $\mathrm{O}$ ganho de peso melhorou $8 \%$ na faixa de 0,18 e $0,31 \%$ de $P d$, a partir da qual as médias não diferiram entre si. Trabalhando com frangos de corte nos períodos de 32 a 42 e de 42 a 49 dias de idade, Dhandu \& Angel (2003) não encontraram efeitos sobre as características de desempenho. Esses autores relataram que essas variáveis não são indicadores sensíveis para avaliar as exigências de fósforo disponível em frangos com idades mais avançadas.

Os resultados de conversão alimentar das aves de ambos os sexos ajustaram-se ao modelo quadrático, que estimou o nível ótimo de $0,351 \%$ de Pd na ração para reduzir a conversão alimentar, equivalente a consumo de 8,45 e 6,70 g de Pd/ave para machos e fêmeas, respectivamente. As aves que receberam rações com níveis abaixo e acima desse valor apresentaram os piores valores de conversão alimentar (Tabela 4). Os níveis crescentes de fósforo disponível aumentaram o consumo de ração, porém não refletiram em melhor ganho de peso, visto que os três maiores níveis proporcionaram ganhos de peso iguais. Dessa forma, o acréscimo no ganho de peso não acompanhou, na mesma magnitude, o aumento do consumo de ração, o que piorou a conversão alimentar das aves que receberam os níveis 0,18 e $0,57 \%$ de Pd. Assim, a deficiência quanto o excesso de fósforo são prejudiciais, pois, de acordo com Runho et al. (2001) e Gomes et al. (2004), o aproveitamento dos nutrientes pode reduzir com a formação de complexos insolúveis.

Os resultados do teor de fósforo na tíbia das aves machos e fêmeas foram ajustados pelos modelos propostos. Os níveis de 0,495 e 0,343\% de fósforo disponível na ração 
Tabela 5 - Equações ajustadas, coeficientes de determinação $\left(\mathrm{R}^{2}\right)$ e níveis de fósforo disponível estimados para aves ISA Label de 28 a 56 dias de idade

\begin{tabular}{|c|c|c|c|}
\hline Modelo & Variável/Equação & NPd (\%) & $\mathrm{R}^{2}$ \\
\hline Linear & $\begin{array}{l}\text { Consumo de fósforo disponível (g/ave) - Macho } \\
\mathrm{CPd}=-0,6205+25,8365 \mathrm{Pd} \\
\text { Consumo de fósforo disponível (g/ave) - Fêmea }\end{array}$ & - & 0,99 \\
\hline Linear & $\begin{array}{l}\mathrm{CPd}=-0,4159+20,2641 \mathrm{Pd} \\
\text { Conversão alimentar }(\mathrm{g} / \mathrm{g})\end{array}$ & - & 0,99 \\
\hline Quadrático & $\begin{array}{l}\mathrm{CA}=2,3773-1,2322 \mathrm{Pd}+1,7524 \mathrm{Pd}^{2} \\
\text { Fósforo na tíbia }(\%)-\text { Machos e Fêmeas }\end{array}$ & 0,351 & 0,82 \\
\hline LRP & $\mathrm{PT}=9,005-3,444(0,3427-\mathrm{Pd})$ & 0,343 & 0,99 \\
\hline Quadrático & $\mathrm{PT}=7,6004+5,8405 \mathrm{Pd}-5,8973 \mathrm{Pd}^{2}$ & 0,495 & 0,98 \\
\hline Quadrático + LRP & $\begin{array}{l}\left(-5,840+\left(5,840^{2}-4 \times(-5,897 \times(7,60-9,00))\right)^{1 / 2} /(2 \times 5,897)\right. \\
\text { Cinzas na tíbia }(\%)-\text { Machos e fêmeas }\end{array}$ & 0,411 & - \\
\hline LRP & $\begin{array}{l}\mathrm{CT}=48,0517-22,2266(0,2909-\mathrm{Pd}) \\
\text { Resistência à quebra óssea }(\mathrm{kgf} / \mathrm{mm})-\text { Machos e fêmeas }\end{array}$ & 0,291 & 0,95 \\
\hline LRP & $\mathrm{RQO}=18,0855-42,4723(0,2762-\mathrm{Pd})$ & 0,276 & 0,90 \\
\hline Quadrático & $\mathrm{RQO}=4,3898+70,2611 \mathrm{Pd}-84,536 \mathrm{Pd}^{2}$ & 0,415 & 0,87 \\
\hline Quadrático + LRP & $\left(-70,261+\left(70,261^{2}-4 \times(84,536 \times(4,389-18,08))\right)^{1 / 2} /(2 \times 84,536)\right.$ & 0,310 & - \\
\hline
\end{tabular}

foram estimados pelos modelos quadrático e LRP, respectivamente. Pelo primeiro ponto de interseção da equação quadrática com o platô do LRP, estimou-se o nível ótimo de $0,411 \%$ de Pd que aumenta a deposição fósforo na tíbia das aves no período de 28 a 56 dias de idade. Resultado semelhante foi obtido por Gomes et al. (1994), que estimaram pelo modelo LRP a máxima deposição óssea de fósforo no nível de 0,331\% de Pd na ração para frangos de corte de 22 a 42 dias de idade.

O nível de fósforo disponível que aumenta a deposição de cinzas na tíbia das aves de ambos os sexos foi determinado pelo modelo LRP, o qual forneceu a estimativa de 0,291\%. Em termos percentuais, esse resultado foi similar aos obtidos por Gomes et al. (2004), que é de 0,303\% de Pd para frangos de corte machos de 22 a 42 dias.

A resistência à quebra óssea foi ajustada pelo modelo quadrático, que estimou o nível de $0,415 \%$ de Pd na ração para melhorar essa variável em aves machos e fêmeas na fase de crescimento. Entretanto, o ajuste pelo modelo LRP e a associação dos dois modelos (quadrático com LRP) estimou os níveis de 0,276 e 0,310\% de Pd, respectivamente. Na fase inicial de vida, o tecido ósseo possui prioridade em crescimento. Dessa forma, mesmo que a ave esteja em desenvolvimento aos 56 dias de idade, o crescimento do esqueleto não é tão acentuado como na fase inicial. Provavelmente, nesta fase as aves alimentadas com rações deficientes em fósforo disponível sejam mais propensas em apresentar problemas de resistência óssea que na fase anterior, devido à partição do fósforo para os outros tecidos. Isso justifica o efeito da redução na resistência à quebra óssea das aves que receberam rações deficientes em fósforo disponível. Vargas Junior et al. (2004) avaliaram as exigências de cálcio e fósforo disponível para aves de reposição leves e semipesadas e também relataram que aves jovens em crescimento precisam desenvolver a estrutura óssea para sustentar o peso corporal, enquanto, na fase de produção, o osso está formado e ave passa a necessitar de cálcio para formação da casca dos ovos.

Na fase final, 56 a 84 dias de idade, os níveis de fósforo disponível das rações influenciaram $(\mathrm{P}<0,05)$ todas as variáveis analisadas (Tabela 6). No entanto, não foi verificado efeito $(\mathrm{P}>0,05)$ na deposição de cálcio na tíbia e na resistência à quebra óssea. Entre as variáveis analisadas, não houve efeito de sexo $(\mathrm{P}>0,05)$ na deposição de fósforo, cálcio e cinzas na tíbia. A interação entre os fatores estudados para consumos de ração e de fósforo disponível e conversão alimentar evidenciou que as respostas aos níveis de fósforo disponível da ração no período dependem do sexo.

Com o desdobramento da interação para o consumo de ração das aves, obteve-se ajuste adequado pelo modelo LRP (Tabela 7). Os níveis que melhoraram o consumo de ração foram de 0,453 e 0,217\% de Pd para machos e fêmeas, respectivamente. Da mesma forma, a interação entre os fatores para consumo de fósforo disponível estimou equações distintas para machos e fêmeas, devido às variações no consumo de ração entre os sexos.

Conforme os resultados da análise de variância, os níveis de fósforo disponível da ração afetaram $(\mathrm{P}<0,05) \mathrm{o}$ ganho de peso, porém não foi possível nenhum ajuste pelos modelos estudados, assim, utilizou-se o teste Duncan para comparar as médias. As aves que receberam ração com 0,14\% de fósforo disponível apresentaram menor ganho de peso em comparação àquelas que receberam 0,27\%, que, por sua vez, não diferiram das demais. Esse resultado justifica-se pelo fato de que o menor nível $(0,14 \%)$ está muito abaixo daqueles relatados na literatura para frangos 
Tabela 6 - Desempenho de aves ISA Label machos e fêmeas alimentadas com rações contendo quatro níveis de fósforo disponível no período de 56 a 84 dias de idade

\begin{tabular}{|c|c|c|c|c|c|c|c|c|c|c|}
\hline \multirow[t]{2}{*}{ Variável } & \multicolumn{3}{|c|}{ Probabilidade } & \multirow[t]{2}{*}{ Sexo } & \multicolumn{4}{|c|}{ Nível de fósforo disponível (\%) } & \multirow[t]{2}{*}{ Média } & \multirow[t]{2}{*}{ CV (\%) } \\
\hline & Fósforo disponível & Sexo & $\mathrm{Pd}^{*}$ sexo & & 0,14 & 0,27 & 0,40 & 0,53 & & \\
\hline \multirow[t]{3}{*}{ Consumo de ração (g/ave) } & 0,0041 & 0,001 & 0,0180 & Macho & 3496 & 3550 & 3774 & 3803 & 3656 & 2,69 \\
\hline & & & & Fêmea & 2828 & 2993 & 2944 & 2909 & 2919 & \\
\hline & & & & Média & 3162 & 3272 & 3359 & 3356 & & \\
\hline \multirow[t]{3}{*}{ Consumo de fósforo disponível (g/ave) } & 0,0001 & 0,0001 & 0,0004 & Macho & 4,89 & 9,59 & 15,10 & 20,15 & 12,43 & 2,99 \\
\hline & & & & Fêmea & 3,96 & 8,08 & 11,78 & 15,42 & 9,81 & \\
\hline & & & & Média & 4,43 & 8,83 & 13,44 & 17,78 & & \\
\hline \multirow[t]{3}{*}{ Ganho de peso (g/ave) } & 0,0035 & 0,0001 & 0,1540 & Macho & 911 & 998 & 1110 & 1051 & 1018 & 6,61 \\
\hline & & & & Fêmea & 651 & 772 & 735 & 728 & 722 & \\
\hline & & & & Média & $781 \mathrm{~B}$ & 885A & 923A & $890 \mathrm{~A}$ & & \\
\hline \multirow[t]{3}{*}{ Conversão alimentar (g/g) } & 0,0001 & 0,0001 & 0,0396 & Macho & 3,838 & 3,557 & 3,406 & 3,525 & 3,582 & 3,53 \\
\hline & & & & Fêmea & 4,649 & 3,875 & 4,005 & 3,999 & 4,132 & \\
\hline & & & & Média & 4,244 & 3,716 & 3,706 & 3,762 & & \\
\hline \multirow[t]{3}{*}{ Fósforo na tíbia (\%) } & 0,0280 & 0,2364 & 0,3819 & Macho & 7,43 & 8,23 & 8,12 & 8,28 & 8,01 & 5,11 \\
\hline & & & & Fêmea & 8,18 & 8,20 & 8,04 & 8,43 & 8,22 & \\
\hline & & & & Média & 7,78 B & $8,11 \mathrm{~A}$ & $8,26 \mathrm{~A}$ & $8,31 \mathrm{~A}$ & & \\
\hline \multirow[t]{3}{*}{ Cálcio na tíbia (\%) } & 0,5609 & 0,1271 & 0,4981 & Macho & 14,51 & 15,79 & 16,02 & 16,33 & 15,35 & 6,04 \\
\hline & & & & Fêmea & 15,72 & 15,37 & 15,52 & 16,00 & 15,97 & \\
\hline & & & & Média & 15,27 & 15,62 & 16,06 & 15,68 & & \\
\hline \multirow[t]{3}{*}{ Cinzas na tíbia (\%) } & 0,0160 & 0,2758 & 0,1191 & Macho & 40,60 & 44,67 & 44,18 & 44,55 & 43,77 & 4,22 \\
\hline & & & & Fêmea & 45,91 & 43,91 & 44,17 & 45,62 & 44,63 & \\
\hline & & & & Média & 42,39 & 45,04 & 44,61 & 44,76 & & \\
\hline \multirow[t]{3}{*}{ Resistência à quebra óssea (Kgf/mm) } & 0,5229 & 0,0001 & 0,3141 & Macho & 26,90 & 27,80 & 22,33 & 21,45 & 28,25 & 8,84 \\
\hline & & & & Fêmea & 30,21 & 28,08 & 21,28 & 19,59 & 21,16 & \\
\hline & & & & Média & 24,61 & 25,75 & 24,63 & 23,83 & & \\
\hline
\end{tabular}

Médias seguidas de letras iguais nas linhas (maiúscula) não diferem entre si $(p>0,05)$ pelo teste Duncan. CV = coeficiente de variação.

Tabela 7 - Equações ajustadas, coeficientes de determinação $\left(\mathrm{R}^{2}\right)$ e níveis de Pd estimados (NPd) para aves ISA Label de 56 a 84 dias de idade

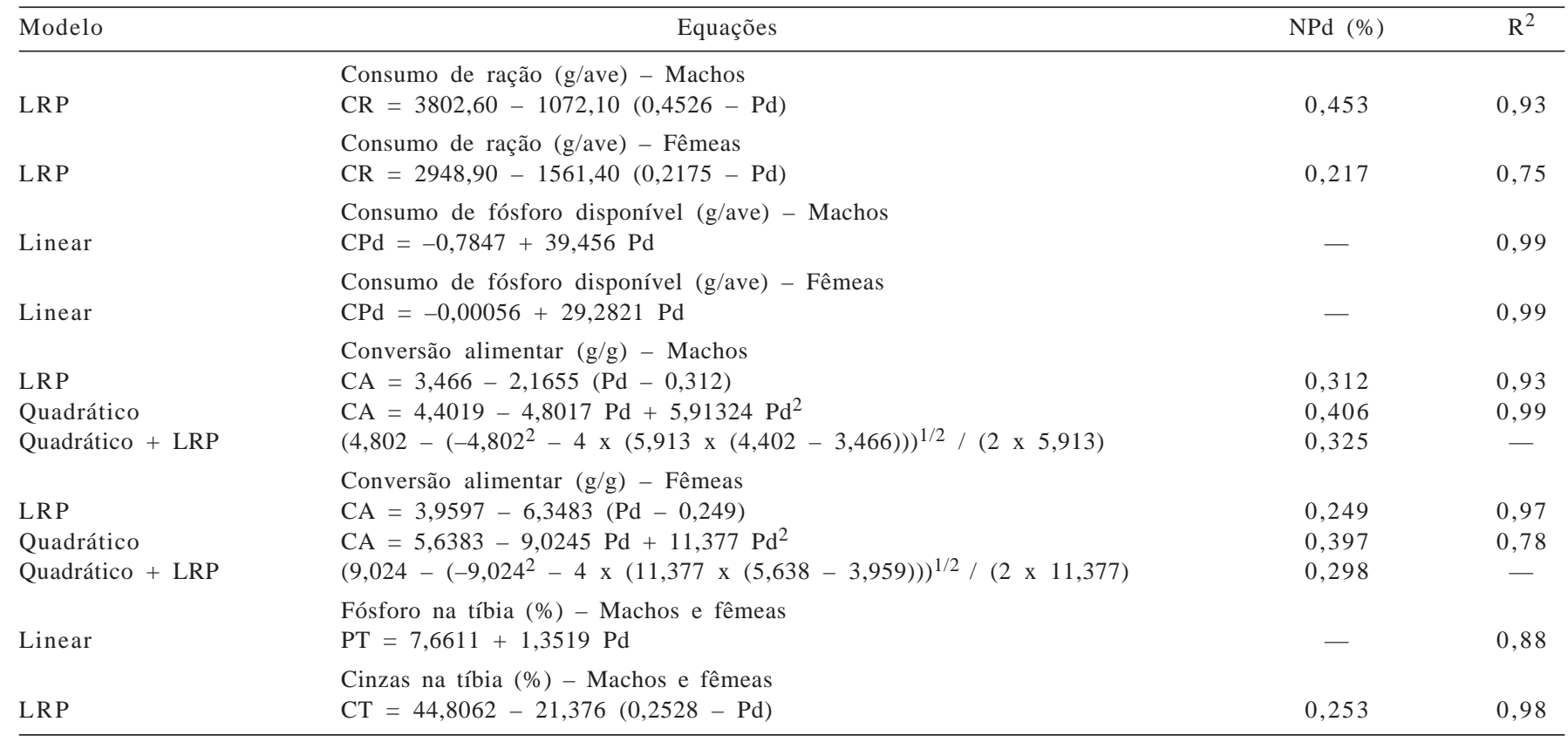

de corte. $\mathrm{O}$ aumento observado no ganho de peso entre o nível de 0,14 e 0,27\% de fósforo disponível foi de $12 \%$.

Para a conversão alimentar, verificou-se interação $(\mathrm{P}<0,05)$ entre os níveis de $\mathrm{Pd}$ e sexos avaliados, sendo ajustados pelos modelos propostos, tanto para os resultados de machos quanto de fêmeas. Para os machos foram estimados os níveis de 0,406\% de Pd pelo modelo quadrático e 0,312\% pelo LRP e pela associação dos modelos, obteve o nível ótimo de $0,325 \%$ de Pd na ração para fase de 56 a 84 dias de idade. No entanto, os resultados das fêmeas apresentaram estimativas dos níveis de 0,397\% de Pd na ração pelo modelo quadrático e $0,249 \%$ de Pd pelo LRP. A 
interseção da equação quadrática com o platô do LRP estimou o nível de $0,298 \%$ de Pd na ração que minimiza a CA das fêmeas na fase final.

Avaliando os resultados do teor de fósforo na tíbia verificou-se que somente a equação linear crescente ajustou-se aos resultados. Pela análise das médias, constatou-se que o nível de $0,14 \%$ de Pd apresentou a menor deposição de fósforo na tíbia, demonstrando que este nível não foi suficiente para promover adequada mineralização óssea.

O teor de cinzas na tíbia das aves de ambos os sexos ajustou-se somente pelo modelo LRP, com estimativa de 0,253\% como o melhor nível de fósforo disponível na ração. Avaliando a exigência de fósforo disponível para frangos de corte na fase de terminação, Gomes et al. (1994) estimaram o nível de 0,333\% para máxima deposição de cinzas na tíbia, no entanto, em outro trabalho, Gomes et al. (2004) não constataram diferenças significativas entre os níveis de fósforo disponível das rações para frangos de corte de 43 a 53 dias de idade.

Os níveis de fósforo disponível avaliados não afetaram $(\mathrm{P}>0,05)$ a resistência à quebra óssea. De acordo com Pizzauro Júnior (2002), a integridade mecânica do osso é mantida por um ciclo regular de remodelação e formação óssea e esse processo pode explicar porque aves em idade avançada, mesmo quando alimentadas com rações moderadamente deficientes em fósforo, são mais tolerantes a essa deficiência. Esse fato pode justificar a ausência de efeito dos níveis de fósforo sobre a resistência óssea à quebra nessa fase, pois aves mais velhas não necessitam de grande aporte de minerais na ração para suprir suas exigências para crescimento do tecido ósseo.

\section{Conclusões}

Machos e fêmeas da linhagem ISA Label necessitam, respectivamente, no período de 1 a 28 dias de idade, de 0,39 e $0,49 \%$ de fósforo disponível na ração. No período de 28 a 56 dias de idade, recomenda-se $0,35 \%$ de fósforo disponível na ração, independentemente do sexo e, no período de 56 a 84 dias de idade, 0,32 e 0,30\% para machos e fêmeas, respectivamente.

\section{Referências}

BAR, A.; SHINDER, D.; YOSEFI, S. et al. Metabolism and requirements for calcium and phosphorus in the fast-growing chicken as affected by age. British Journal of Nutrition, v.89, p.51-60, 2003.

BRUGALLI, I.; SILVA, D.J.; ALBINO, L.F.T. et al. Exigência de fósforo disponível e efeito da granulometria na biodisponibilidade de fósforo da farinha de carne e osso para pintos de corte. Revista Brasileira de Zootecnia, v.28, n.6, p.1288-1296, 1999.

DHANDU, A.S.; ANGEL, R. Broiler nonphytin phosphorus requirement in the finisher and withdrawal phases of a commercial four-phase feeding system. Poultry Science, v.82, p.1257-1265, 2003.

GOMES, P.C.; GOMES, M.F.M.; ALBINO, L.F.T. et al. Exigências de fósforo disponível para frangos de corte nas fases de crescimento e terminação. Revista Brasileira de Zootecnia, v.23, n.4, p.615-622, 1994.

GOMES, P.C.; RUNHO, R.C.; D’AGOSTINI, P. et al. Exigência de fósforo disponível para frangos de corte machos e fêmeas de 22 a 42 e 43 a 53 dias de idade. Revista Brasileira de Zootecnia, v.33, n.6, p.1734-1746, 2004 (supl. 1).

GONZALES, E.; SARTORI, J.R. Crescimento e metabolismo muscular. In: MACARI, M.; GONZALES, E. (Eds.) Fisiologia Aviária aplicada a frangos de corte. 2.ed. Jaboticabal: FUNEP, 2002. p.168-170.

McDOWELL, R.L. Calcium and phosphorus. In: Minerals in animal and human nutrition. San Diego: Academic Press, 1992. p.31-32.

PIZZAURO JÚNIOR, J.M. Hormônios e regulação do metabolismo do tecido ósseo. In: MACARI, M.; FURLAN, R.L.; GONZALES, E. (Eds.) Fisiologia aviária aplicada a frangos de corte. 2.ed. Jaboticabal: FUNEP, 2002. p.268-269.

ROstagno, H.S.; ALBINO, L.F.T.; DOnZELE, J.L. Tabelas brasileiras para aves e suínos (composição de alimentos e exigências nutricionais). Viçosa, MG: UFV, 2005. 186p.

RUNHO, R.C.; GOMES, P.C.; ROSTAGNO, H.S. et al. Exigência de fósforo disponível para frangos de corte machos e fêmeas de 1 a 21 dias de idade. Revista Brasileira de Zootecnia, v.30, n.1, p.187-196, 2001.

SAKOMURA, N.K.; ROSTAGNO, H.S. Métodos de pesquisa em nutrição de monogástricos. Jaboticabal: FUNEP, 2007. 283p.

SILVA, D.J.; QUEIROZ, A.C. Análise de alimentos: métodos químicos e biológicos. 3.ed. Viçosa, MG: UFV, 2002. 165p.

STATISTICAL ANALYSES SYSTEM - SAS. SAS User's guide: statistics. Version. 9.1, 2.ed. Cary: SAS Institute Inc., 2009. 20p.

UNDERWOOD, E.J.; SUTTLE, N.F. Calcium. In: ____-_.The mineral nutrition of livestock. 3.ed. Wallingford: Cabi Publishing, 1999. p.67-104.

VARGAS JUNIOR, J.G.; ALBINO, L.F.T.; ROSTAGNO, H.S. et al. Níveis nutricionais de cálcio e de fósforo disponível para aves de reposição leves e semipesadas de 13 a 20 semanas de idade. Revista Brasileira de Zootecnia, v.33, n.5, p.1263-1273, 2004.

ZOOLLITSCH, W.; ZHIQIANG, C.; PEGURI, A. et al. Nutrient requirements of laying hens. In: SIMPÓSIO INTERNACIONAL SOBRE EXIGÊNCIAS NUTRICIONAIS DE AVES E SUÍNOS, 1996, Viçosa, MG. Anais... Viçosa, MG: Universidade Federal de Viçosa, 1996. p.109-159. 